\title{
Transient mutism and cerebellar ischemic stroke: case report
}

\author{
Luis Rafael Moscote-Salazar ${ }^{1}$, Hernando Alvis-Miranda ${ }^{1}$, Angel Lee ${ }^{2}$, \\ Hector Farid Escorcia ${ }^{3}$, Sandra Milena Castellar-Leones ${ }^{1}$ \\ ${ }^{1}$ Universidad Cartagena, Colombia \\ ${ }^{2}$ Hospital Angeles del Pedregal, México D.F, México \\ ${ }^{3}$ Hospital Universitario CARI, Barranquilla, Colombia
}

\begin{abstract}
The ischemic stroke is one of the most common conditions in our hospitals, representing $50 \%$ of revenues of neurology services. A variety of processes is cerebral ischemic myocardial cerebellum. Cerebellar infarction is not a rare disease, representing between 2 to $4 \%$ of all cerebrovascular events in clinical and autopsy series, and their ratio is 4-5 times higher than cerebellar hemorrhage. Although it is increasingly documented, it rarely Recognized stills like a phenomenon. Mutism occurs primarily in children and occasionally in adults as a well-recognized complication of posterior fossa surgery. Rarely been reported transient mutism associated with cerebellar infarction as isolated episode.
\end{abstract}

Key word: stroke, transient mutism, neurosurgery.

\section{Introduction}

Cerebrovascular diseases are a major cause of death in the world. The Health Report in the World, published by the World Health Organization 2003, cerebrovascular disease places fourth among those responsible for the global burden of disease for over 15 years, reaching the second in the population over 60 years. Among the many presentations of ischemic cerebrovascular disease is ischemia cerebellum.

The patient's neurological deterioration with cerebellar infarction is attributed to edema. Medical management includes steroids, mannitol, barbiturates and hyperventilation. The symptomatology correspond to the classical cerebellar data. We present an unusual case characterized by sudden onset mutism in the context of cerebellar infarction progressing to acute hydrocephalus resolved by placement of a ventriculo peritoneal shunts

\section{Case report}

A man of 55 years with a history of hypertension uncontrolled blood enters the emergency department by moderate headache clinical picture and language disturbance. No history of drug use. Occasional alcohol consumption. The story did not report symptoms of anxiety or depression. Neurological examination the patient was silence. Biochemical tests were normal. Imaging studies were performed which showed the presence of a cerebellar infarction. (Figure 1) After 24 hours, the patient has neurological impairment whereby framework are images and acute hydrocephalus evidence, decides to place ventriculoperitonealshunt. The patient presented 24 hours disappearance of mutism and responded to commands. Was discharged after 15 days. 

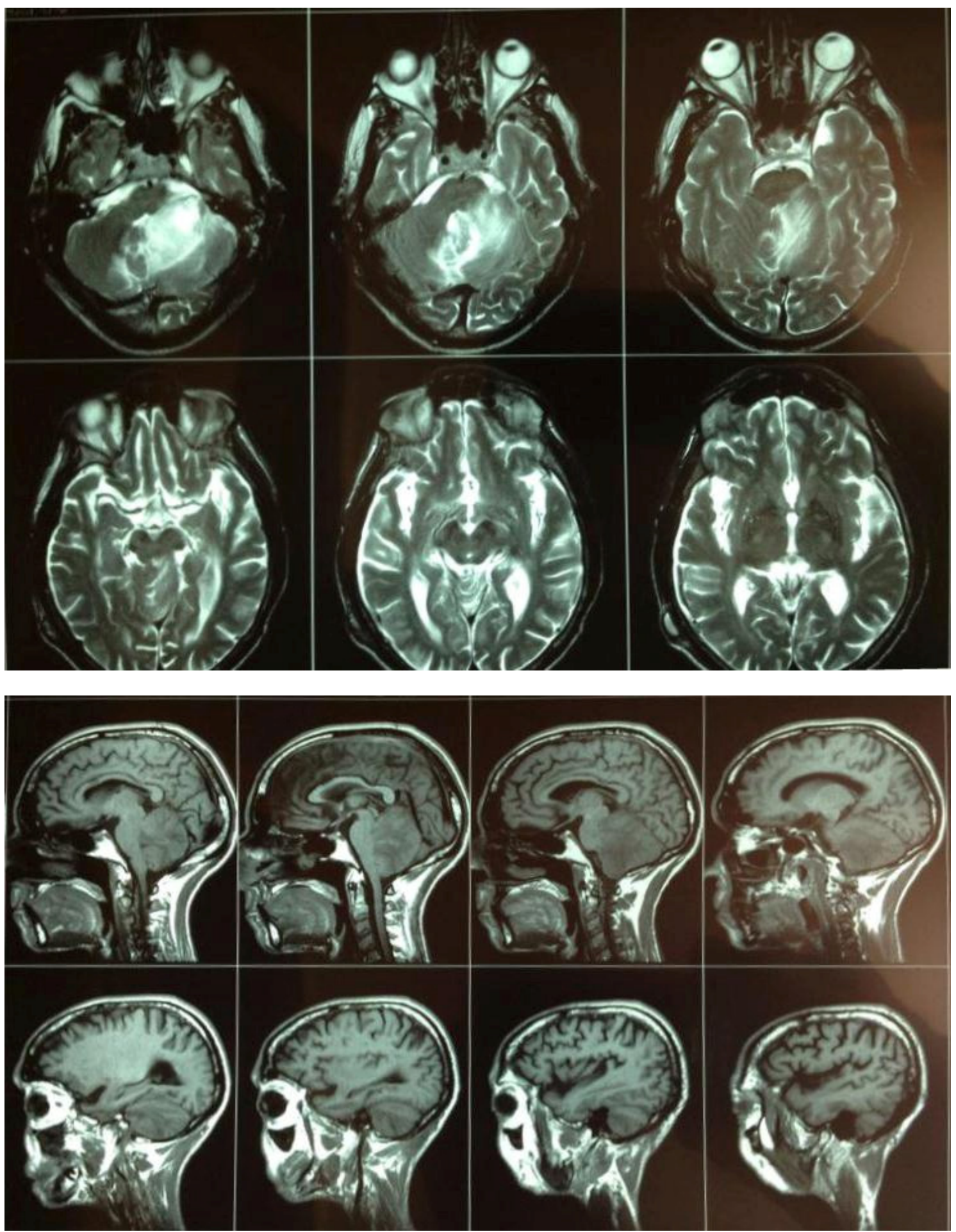

Figure 1

IRM postoperative reveals a cerebellar stroke 


\section{Discussion}

Cerebellar mutism (CM) is a form of severe dysarthria marked by profound impairment of fluency, articulation, and modulation of speech (1), resulting in the absence or marked pause of verbal output $(2,3)$ that is, anarthria (4). It only applies for cases whereby lesions of the cerebellum are associated with the onset of the mutism and do not have corresponding long tract signs, supra, cranial nerve palsies (5) or impaired consciousness $(5,6)$. The first mention of CM as a distinct clinical entity was reported in 1985 by Rekate et al (7) and Yonemasu (8).Particularly, Holmes noted that lesions of thecereballar hemispheres alone were enough to cause dysarthria, but when the vermis was involved, appears a greater difficulty in phonation and articulation $(9,10)$.

Although it is increasingly documented, it stills like a rarely recognized phenomenon (11). Mutism occurs primarily in children and occasionally in adults as a well-recognized complication of posterior fossa surgery (4, 5).In general, mutism caused by intracranial surgical intervention has been described in the following areas (12): Broca's area;the anterior cingulate area; the descending tracts bilaterally;the mesencephalic reticular formation; after callosotomy for medically intractable epilepsy; the supplementary motor area; and in the midline cerebellar structures (13).

have been reported that there are many lesions and locations within the posterior fossa that create a pathologic consequence related to speech disorders (14). Continuously growing insights in the neuroanatomy of cerebellum, evidence from functional neuroimaging, neurophysiological research and advancements in clinical and experimental neurosychology contributed to the view that human cerebellum participates in a much wider range of functions than conventionally accepted $(15,16)$.

The most common feature of CM is its transient nature, which has been explained by cerebral vasospasm (17). Nevertheless, Turgut (18) speculated that hydrocephalus, rather than the vasospasm, is a possible exacerbating factor in the development of $\mathrm{CM}$, due to the delayed transient ischemia secondary to that process occurs after surgery on the cerebellum but not in other parts of the brain, possibly owing to the existence of more sensitive Purkinje cells (11). CM is often associated with a particular behavior characterized by irritability and disturbances in socialization and communication ranging from emotional lability to autistic withdrawal (19-23).

Coplin et al. (24) in 1997, made the first report of transient mutism in an adult with neither tumor nor brainstem infarction, they presented a case of transient mutism of four month long in a patient after cereberal hemorrhage, the patient cannot return to his normal speech. His speech was characterized by great effort, ataxic dysarthria, and strained voice, with pitch often higher than normal. This documents the importance of cerebellar structures for initiation and production of speech in adulthood.

Marien et al. (16) present the case of a 73-years old patient with ischaemic lesion in the vascular territory of the right arteriacerebellaris superior, that induced a prefrontal aphasic syndrome and an agrammatism. The patient acutely developed cerebellar and brainstem symptoms. Cerebellar involvement 
reflected by slight dysarthric speech problems and right-sided dysdiadochokinesia, dysmetria, and rebound phenomena. Six months postonset, a dysarthric syndrome was found which cardinal features consisted of: articulatory imprecisions; phoneme iterations and syllable repetitions; irregular articulatory breakdowns and intervals; and slow rate. No stress aberrations, vowel prolongations, vowel distortions, harsh voice quality, loudness alternations, rate variability, altered nasality, voice tremor, task-dependency or audible inspiration were noted. Given the presumed common substrate of an articulatory timing deficiency, the constellation of the dysarthric symptoms in this patient, the authors corroborated the view that temporal dysregulation might act as the primary component in impaired motor planning of speech after cerebellar lesions.

Mewasingh et al. (4), described the cases of two children who developed transient CM accompanied by a characteristic behavior associated with non-surgical causes.Ischemic cerebellar infarction caused by hemolytic-uremic syndrome in one child and cerebellitis in the other. In both children, anarthria was followed by dysarthria. The two cases presented a behavioral pattern similar to that in postoperative mutism [Classically transient, with lack of cranial nerve dysfunction and long-tract signs, comprehension remains unaffected,a period of intact speech usually occurs and lasts from a few hours to several days $(1,13,20,25-31)]$. There is one case reported of transient mutism related to ischemic process secondary to traumatic injury of the vertebral artery, not located in cerebellum but in brain stem (32).
Most cases of CM described in the literature occur in children undergoing posterior fossa surgery for medulloblastoma or astrocytoma; but it is also described in adults after resection of a posterior fossa tumor such as hemangioblastoma or posterior circulation infarction or hematoma.

Cerebellum is part of a network of cerebello-cerebral/cerebro-cerebellar connections that process and mediate complex social and cognitive behaviors (19, $21,33)$, its role in speech has expanded to include the cognitive component of speech generation, including the internal generation of words, choice of words, rehearsal of speech, timing of speech, and vocal intonations used during speech production $(5,34-38)$. Human brain functional anatomy investigations by PET activation, magnetic resonance imaging and cerebral blood flow studies convincingly demonstrate the participation of cerebellar structures in non-motor tasks such as the mental association of a word with its use, mental arithmetic, mental imagery and stereognosic and associative procedural learning $(15,16)$.

The orofacial muscles are coordinated by the paravermal regions of the cerebellum during speech, probably, the loss of coordination in those muscles movements is primarily responsible for the development of mutism (5). van Mourik et al (39) observed that the time course of mutism can be characterized by the recovery of simple orofacial movements, and the recovery of complex orofacial movements coincides with the disappearance of mutism.

Our case represents a rare presentation of ischemic phenomena of cerebellar mutism should be considered as a possible 
form of disease onset cerebellar ischemic stroke.

\section{Correspondence:}

Dr. Luis Rafael Moscote-Salazar, University of

Cartagena, Cartagena de Indias, Colombia, Southamerica.

\section{E-mail:mineurocirujano@aol.com}

\section{References}

1.Nagatani K, Waga S, Nakagawa Y. Mutism after removal of a vermian medulloblastoma: cerebellar mutism. Surg Neurol. 1991 Oct;36(4):307-9. PubMed PMID: 1948632. Epub 1991/10/01. eng.

2.Altshuler LL, Cummings JL, Mills MJ. Mutism: review, differential diagnosis, and report of 22 cases. The American journal of psychiatry. 1986 Nov;143(11):1409-14. PubMed PMID: 3777229. Epub 1986/11/01. eng.

3.Geschwind N. Current concepts: aphasia. The New England journal of medicine. 1971 Mar 25;284(12):6546. PubMed PMID: 5545606. Epub 1971/03/25. eng. 4.Mewasingh LD, Kadhim H, Christophe C, Christiaens FJ, Dan B. Nonsurgical cerebellar mutism (anarthria) in two children. Pediatric Neurology. 2003 1//;28(1):59-63.

5.Ozgur BM, Berberian J, Aryan HE, Meltzer HS, Levy ML. The pathophysiologic mechanism of cerebellar mutism. Surgical Neurology. 2006 7//;66(1):18-25.

6.Gelabert-Gonzalez M, Fernandez-Villa J. Mutism after posterior fossa surgery. Review of the literature. Clinical neurology and neurosurgery. 2001 Jul;103(2):111-4. PubMed PMID: 11516555. Epub 2001/08/23. eng.

7.Rekate HL, Grubb RL, Aram DM, Hahn JF, Ratcheson RA. Muteness of cerebellar origin. Archives of neurology. 1985 Jul;42(7):697-8. PubMed PMID: 4015467. Epub 1985/07/01. eng.

8.Yonemasu Y. Cerebellar mutism and speech disturbance as a complication of posterior fossa surgery in children. 13th Annual Meeting of the Japanese Society for Pediatric Neurosurgery; Tsukuba, Japan1985.

9.Holmes G. The Croonian Lectures on the clinical symptoms of cerebellar disease and their interpretation. Lecture II. 1922. Cerebellum (London, England). 2007;6(2):148-53; discussion 1. PubMed PMID: 17566247. Epub 2007/06/15. eng.

10.HOLMES G. THE SYMPTOMS OF ACUTE CEREBELLAR INJURIES DUE TO GUNSHOT INJURIES. Brain. 1917 December 1, 1917;40(4):461535 .
11.Turgut M. Re: The pathophysiologic mechanism of cerebellar mutism (Ozgur et al. Surg Neurol 2006;66:18-25). Surgical Neurology. 2007 7//;68(1):117. 12.Tahta K, Cirak B, Pakdemirli E, Suzer T, Tahta F. Postoperative mutism after removal of an anterior falcine meningioma. Journal of Clinical Neuroscience. 2007 8//;14(8):793-6.

13.Ersahin Y, Mutluer S, Cagli S, Duman Y. Cerebellar mutism: report of seven cases and review of the literature. Neurosurgery. 1996 Jan;38(1):605; discussion 6. PubMed PMID: 8747952. Epub 1996/01/01. eng.

14.Lechtenberg R, Gilman S. Speech disorders in cerebellar disease. Annals of neurology. 1978 Apr;3(4):285-90. PubMed PMID: 666268. Epub 1978/04/01. eng.

15.Mariën P, Saerens J, Nanhoe R, Moens E, Nagels G, Pickut BA, et al. Cerebellar induced aphasia: case report of cerebellar induced prefrontal aphasic language phenomena supported by SPECT findings. Journal of the Neurological Sciences. 1996 12//;144(1-2):34-43.

16. Marien P, Engelborghs S, Pickut BA, De Deyn PP. Aphasia following cerebellar damage: fact or fallacy? Journal of Neurolinguistics. 2000 7/15/;13(2-3):145-71. 17.Al-Anazi A, Hassounah M, Sheikh B, Barayan S. Cerebellar mutism caused by arteriovenous malformation of the vermis. British journal of neurosurgery. 2001 Feb;15(1):47-50. PubMed PMID: 11303661. Epub 2001/04/17. eng.

18.Turgut M. Transient "cerebellar" mutism. Child's nervous system : ChNS : official journal of the International Society for Pediatric Neurosurgery. 1998 Apr-May;14(4-5):161-6. PubMed PMID: 9660116. Epub 1998/07/11. eng.

19.Riva D, Giorgi C. The cerebellum contributes to higher functions during development: evidence from a series of children surgically treated for posterior fossa tumours. Brain. 2000 May;123 ( Pt 5):1051-61. PubMed PMID: 10775549. Epub 2000/04/25. eng.

20.Pollack IF. Posterior fossa syndrome. International review of neurobiology. 1997;41:411-32. PubMed PMID: 9378600. Epub 1997/01/01. eng.

21.Gordon N. Mutism: elective or selective, and acquired. Brain \& development. 2001 Mar;23(2):83-7. PubMed PMID: 11248456. Epub 2001/03/15. eng.

22.Sharkey L, McNicholas F. 'More than 100 years of silence', elective mutism: a review of the literature. European child \& adolescent psychiatry. 2008 Aug;17(5):255-63. PubMed PMID: 18357427. Epub 2008/03/22. eng.

23.Steinhausen HC, Juzi C. Elective mutism: an analysis of 100 cases. Journal of the American Academy of Child and Adolescent Psychiatry. 1996 May;35(5):606-14. PubMed PMID: 8935207. Epub 1996/05/01. eng. 
24.Coplin WM, Kim DK, Kliot M, Bird TD. Mutism in an Adult Following Hypertensive Cerebellar Hemorrhage: Nosological Discussion and Illustrative Case. Brain and Language. 1997 10/1/;59(3):473-93.

25.Dietze DD, Jr., Mickle JP. Cerebellar mutism after posterior fossa surgery. Pediatric neurosurgery. 1990;16(1):25-31; discussion PubMed PMID: 2133406. Epub 1990/01/01. eng.

26.Koh S, Turkel SB, Baram TZ. Cerebellar mutism in children: report of six cases and potential mechanisms. Pediatr Neurol. 1997 Apr;16(3):218-9. PubMed PMID: 9165512. Pubmed Central PMCID: PMC3399684. Epub 1997/04/01. eng.

27.van Dongen HR, Catsman-Berrevoets CE, van Mourik M. The syndrome of 'cerebellar' mutism and subsequent dysarthria. Neurology. 1994 Nov;44(11):2040-6. PubMed PMID: 7969956. Epub 1994/11/01. eng.

28.Aguiar PH, Plese JP, Ciquini O, Marino R. Transient mutism following a posterior fossa approach to cerebellar tumors in children: a critical review of the literature. Child's nervous system : ChNS : official journal of the International Society for Pediatric Neurosurgery. 1995 May;11(5):306-10. PubMed PMID: 7648574. Epub 1995/05/01. eng.

29.Asamoto M, Ito H, Suzuki N, Oiwa Y, Saito K, Haraoka J. Transient mutism after posterior fossa surgery. Child's nervous system : ChNS : official journal of the International Society for Pediatric Neurosurgery. 1994 May;10(4):275-8. PubMed PMID: 7923241. Epub 1994/05/01. eng.

30.D'Avanzo R, Scuotto A, Natale M, Scotto P, Cioffi FA. Transient "cerebellar" mutism in lesions of the mesencephalic-cerebellar region. Acta neurologica. 1993 Aug;15(4):289-96. PubMed PMID: 8249672. Epub 1993/08/01. eng.

31.Mariën P, De Smet HJ, Wijgerde E, Verhoeven J, Crols R, De Deyn PP. Posterior fossa syndrome in adults: A new case and comprehensive survey of the literature. Cortex. 2013 1//;49(1):284-300.

32.Ersahin Y. Transient mutism after brain stem infarction. Acta neurochirurgica. 1999;141(9):1020. PubMed PMID: 10610613. Epub 1999/12/28. eng. 33. Mewasingh LD, Christiaens F, Aeby A, Christophe C, Dan B. Crossed cerebellar diaschisis secondary to refractory frontal seizures in childhood. Seizure : the journal of the British Epilepsy Association. 2002 Dec;11(8):489-93. PubMed PMID: 12464508. Epub 2002/12/05. eng.

34.Ackermann H, Mathiak K, Ivry RB. Temporal organization of "internal speech" as a basis for cerebellar modulation of cognitive functions. Behavioral and cognitive neuroscience reviews. 2004 Mar;3(1):14-22. PubMed PMID: 15191639. Epub 2004/06/12. eng.

35.Decety J, Sjoholm H, Ryding E, Stenberg G, Ingvar DH. The cerebellum participates in mental activity: tomographic measurements of regional cerebral blood flow. Brain research. 1990 Dec 10;535(2):313-7. PubMed PMID: 2073609. Epub 1990/12/10. eng.

36.Ivry R, Fiez J. Cerebellar contributions to cognition and imagery. 2nd ed. Gazzaniga M, editor. Cambridge, MA: MIT Press; 2000.

37.Ivry R, Justus T, Middleton C. The cerebellum, timing, and language: implications for the study of dyslexia. Wolf M, editor: York Press; 2001.

38.Lotze M, Montoya P, Erb M, Hulsmann E, Flor H, Klose U, et al. Activation of cortical and cerebellar motor areas during executed and imagined hand movements: an fMRI study. Journal of cognitive neuroscience. 1999 Sep;11(5):491-501. PubMed PMID: 10511638. Epub 1999/10/08. eng.

39.van Mourik $M$, Catsman-Berrevoets $C E$, van Dongen HR, Neville BG. Complex orofacial movements and the disappearance of cerebellar mutism: report of five cases. Developmental medicine and child neurology. 1997 Oct;39(10):686-90. PubMed PMID: 9352731. Epub 1997/11/14. eng. 